\title{
Determinants In The Choice Of Comprehensible Input Strategies In Science Classes
}

\author{
Crisanta Comia Buri, AMA International University, Kingdom of Bahrain
}

\begin{abstract}
The Bilingual Education Policy, which was launched in 1974 and revised in 1987, has resulted in the limited exposure of Filipino learners to the English language. This is because the policy reversed previous policies and stipulates that in only two content area subjects, namely, Science and Mathematics is English to be used as medium of instruction.

The limited exposure to English has been cited as one of the reasons for the declining proficiency in English of Filipino students since the promulgation of the policy (Gonzales, 1986). On the other hand, the use of English as medium of instruction in cognitively demanding subjects such as science and mathematics has also been given as the reason for the poor showing of students and even teachers themselves in nationwide tests in Science (Maminta, 1985). The overall downtrend in student achievement as evidenced by the poor performance on all of the tests has given rise to two issues concerning the policy. First, is the language for initial literacy and the second is the medium of instruction in science and mathematics. These language issues are crucial in as much as language is the primary vehicle of expression and thought exchange in the classroom. Teaching and learning are in fact language tasks carried out largely by means of verbal interaction between teacher and students (Bellack, et al 1966). The exchange of ideas between students and teachers is largely done through language as they talk about concepts in science, mathematics and other content areas.
\end{abstract}

Keywords: Comprehensible Input Strategies; Teacher-Talk; Content Classes; Pedagogical Modes; Language Acquisition

\section{STATEMENT OF THE PROBLEM}

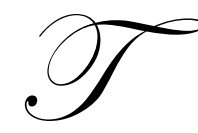

his study attempts to answer the following questions:

1. Is there a difference in the comprehensible input strategies used by teachers in the three modes of teachertalk?

2. Does the ability level of students affect the choice of comprehensible input strategies in the three modes of teacher-talk?

3. Does teaching experience affect the choice of strategies employed in the three modes of teacher-talk?

4. Which of the determinants are significant in the choice of comprehensible input strategies in a science class?

\section{SIGNIFICANCE OF THE STUDY}

This study attempts to compare the comprehensible input strategies employed in the three modes of teacher-talk in high ability and low ability science classes. As such, it hopes to highlight the significant role of content classes like science where English is the medium of instruction in the acquisition of language. In content 
classes, students can acquire language from teacher-talk provided it is comprehensible and just one level above their current proficiency level.

The results of this study can be used in teacher training institutions as a source of language needs of teachers handling content area classes. The findings of this study can also add insights to the growing body of classroom - centered research in content-based language instruction which to date is limited. In addition, this study serves as concrete evidence that the teacher herself is in truth a communicator and a facilitator and she, therefore, should be aware of her language when teaching.

\section{SCOPE AND DELIMITATION OF THE STUDY}

The focus of this study is a comparison of the comprehensible input strategies employed by science teachers in the three modes of teacher-talk. The data gathered is limited to interactions in high and low ability second year science classes in Arellano High School, Division Of City Schools, Manila.

It is further delimited to the moves employed by the teacher in the three pedagogical modes in science class namely: the interactive, informative and operative modes. Where the interactive and operative modes are concerned, it focuses on the preformulations and reformulations employed by the teacher to enable the students to arrive at the correct response. While in the informative mode, it scrutinizes the different moves used to make input comprehensible.

\section{OPERATIONAL DEFINITION OF TERMS}

Experienced teacher - the teacher who has rendered ten or more years of teaching experience.

Novice teacher - the teacher who has rendered one to three years of teaching experience.

Content classes - science classes using English as medium of instruction as stated in the Philippine Bilingual Policy.

High ability classes - refer to students grouped in sections based on their overall achievement the previous year, i, e. with average grades ranging from $85 \%$ and above.

Low ability classes - refer to students grouped in sections based on their overall achievement the previous year, i e. with grades ranging from $75 \%$ to $77 \%$.

Teacher-talk - the teacher's verbal language in teaching science lessons in classrooms. It includes the questions raised, the instructions and information given and the reaction to students' answers.

Language acquisition - the unconscious process of learning a second language through exposure to that language in authentic communication situations; it presupposes that the acquirer is not concerned about linguistic forms or the rules of grammar but with the content or message in the interaction.

Interactive mode - a pedagogical mode characterized by an exchange of talk between two or more interlocutors. It usually takes the form of questions and answers or reactions.

Operative Mode - a pedagogical mode that gives instructions. It usually takes the form of an order or an instruction. In the science class, this is predominant in laboratory work where experiments are carried out.

Informative mode - a pedagogical mode where the teacher provides information. This would be in the form of a lecturette or extended talk on a given topic.

Preformulation - refers to teacher-talk leading to the target question. Its function is to enable the students to answer the question that will be posed. 
Reformulation - refers to the rephrasing of teacher-talk so students will be able to give the correct response to the questions which were not understood at first or in the case of instructions to make them clearer to the person addressed.

Comprehensible input strategies - refer to the effort taken by the teacher in the form of questions or statements to enable students to understand and learn the intended meaning of a concept.

Communication Strategies - refer to the attempts of the students to speak English in order to convey the desired message.

Translation - the act of translating words, phrases and sentences until the desired meaning is understood.

Deviant Forms - are non-syntactic forms, usually questioning strategies to secure the expected response.

Paraphrase - a restatement of a text usually substituting more commonly used words for the expression that are difficult in the original utterance.

Use of Visual Aids - the use of objects as aids to make a concept clear.

Circumlocution - the use of so many words to clarify the term the speaker has in mind.

Code Switching - the shift from the second language to first language to make the meaning clear.

Excessive Coordination - refers to the use of too many conjunctions or linkers resulting in a long, run-on sentence in giving instructions.

Recasting - refers to syntactic revisions made by the teacher in order to clarify an utterance or an expressions.

Repetition - the act of repeating words and phrases until the intended meaning is conveyed.

\section{RELATED LITERATURE}

Krashen's (1982) input hypothesis relates to acquisition not learning it is posits that structure a bit beyond the current level of competence $(i+1)$ of the learner leads to understanding and acquisition of a language. This maybe achieve with the help of context or extra linguistic information. The input hypothesis states that speaking fluency cannot be taught directly. Rather, it "emerges" over time on its own. The best way and the only way to teach speaking according to this view is to provide comprehensible input.

There are basically two ways in which the teacher can aid comprehension, linguistic and non-linguistic. Studies have shown that there are many things speakers do linguistically to make their speech more comprehensible to less competent speakers. Hatch (1979) has summarized the linguistic aspects of simplified input which appear to promote comprehension.

Sinclair and Coulthard (1975) proposed a system of discourse analysis. They set a rank scale model consisting of lesson, transaction, exchange, move and act. According to them, when analyzing classroom interaction, the lesson may be divided into transactions which in turn are made up of exchanges either free or bound exchanges. Among the former are teaching exchanges. Among the latter are reinitiation $(i)$ when no response is made, reinitiation ( $i i)$ when the response is wrong, listing where the expected response consists of a number of items, reinforce and repeat. Of interest to this study are the first two. 


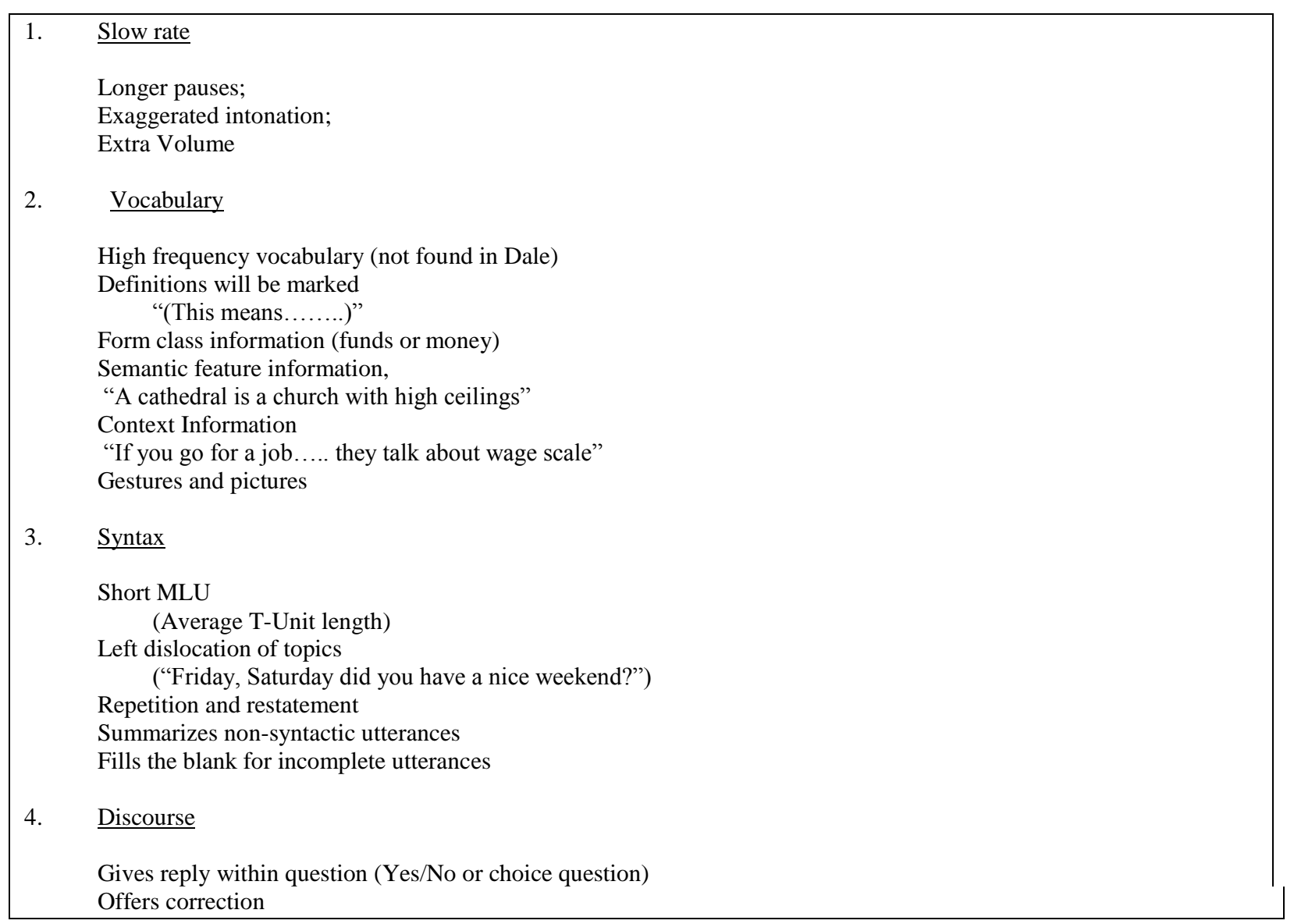

Figure 1: The Linguistic Aspects of Simplified Input

Chaudron (1988) claims that in classrooms the teacher tries to ensure a correct response through preformulations and reformulations. The former are strategies employed to enable listeners to comprehend what is uttered and to respond accordingly. Should the listener still fail to comprehend, then the interlocutor renegotiates the exchange using certain techniques or strategies to bring it back on track. These strategies are called reformulations. A reformulation, which is employed where there is no response and one that is made when the initial answer is wrong would correspond to Sinclair and Coulthard's reinitiation (i) and reinitiation (ii) respectively. In this study, preformulations were scrutinized as comprehensible input strategies especially in the operative and informative mode whereas reformulations were studied particularly in the interactive mode.

Johnson, Chan and Shek (1986) pointed out three aspects of teacher-talk: physiological, interpersonal, and pedagogical. Figure 2 illustrates what they consider the role of teacher-talk to be in the curriculum process. The figure shows that language is used to effect learning. Language could be oral or written. The former, which is the concern of this paper consists of pupil talk and teacher talk. Teacher talk, in turn, is shown to have three aspects: physiological, interpersonal and pedagogical. 


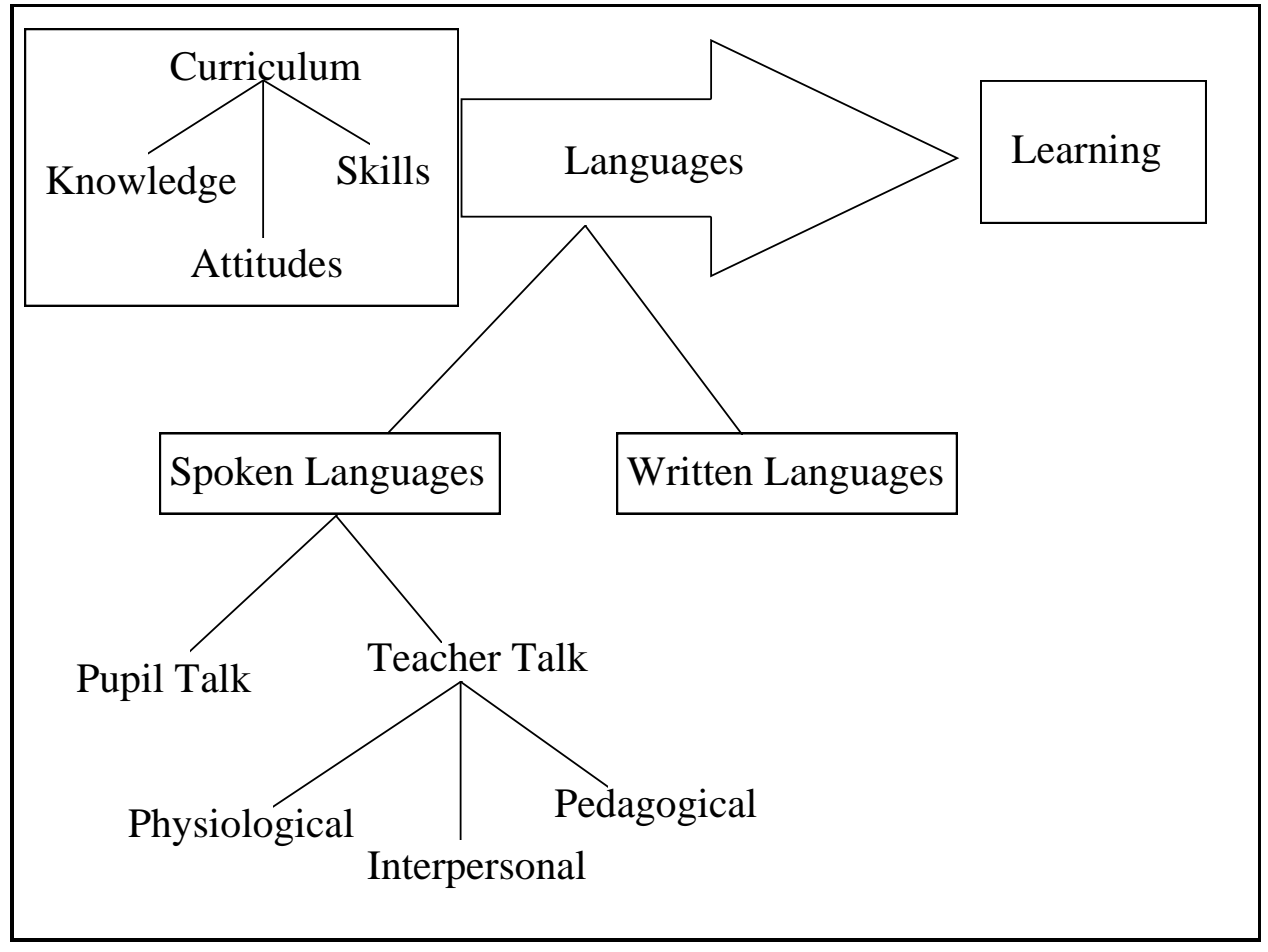

Figure 2: Teacher-talk in the Curricular Process

The physiological aspect relates to the production of oral sounds. In classrooms throughout the world, the major educational resource is, and is likely to remain, the teacher's voice. It is necessary for teachers to speak loudly and clearly enough to be understood and to produce vocal sounds in such a way so as to avoid physical and psychological strain. The teacher's voice should ideally be as rich and as varied an instrument as that of an actor, but is rarely so, and teacher training programs seldom offer assistance in this area.

Reasons are given for the lack of emphasis placed on the physiological aspect. First, as societies have become more egalitarian, regional and foreign accents are more acceptable with the effect that intensive training in the production of native speaker-like talk has become comparatively rare. Secondly, emphasis in linguistic studies has shifted away from articulatory phonetics to a broader interest in morphology syntax, discourse, structure and semantics. In teacher education, there has also been a shift in emphasis, i.e. from teacher-centered to learnercentered teaching approaches. Learner autonomy, individualized instruction, group work, pair work, etc. are now underscored and the teacher's role is viewed as the manager of teaching resource in the classroom.

The Interpersonal Aspect, on the other hand, includes classroom management and socialization. These cover the establishment of teaching and learning conditions and the social climate of the classroom, defining the respective roles of the participants and good interpersonal relationships between the teacher and the individual pupils, groups and the class as a whole.

Despite the degree of importance which educational theory places upon this aspect of the educational enterprise, it too is largely de-emphasized for a number of reasons. There is little empirical evidence that a particular teaching style will result in better learning of their linguistic correlates. Then, too, there are a few, if any, objective ways for determining the means for obtaining a "good" classroom climate. Moreover, the definition of a good classroom climate itself is a problem since it necessarily involves some subjective value judgments, which are expected to be universal. 
The most fully developed component of teacher talk is the pedagogical aspect.

Within the pedagogical aspect of teacher-talk, there are three functional modes: Interactive, Operative and Informative. The present study will analyze the comprehensible input strategies employed in these pedagogical modes of teacher-talk in a science classroom.

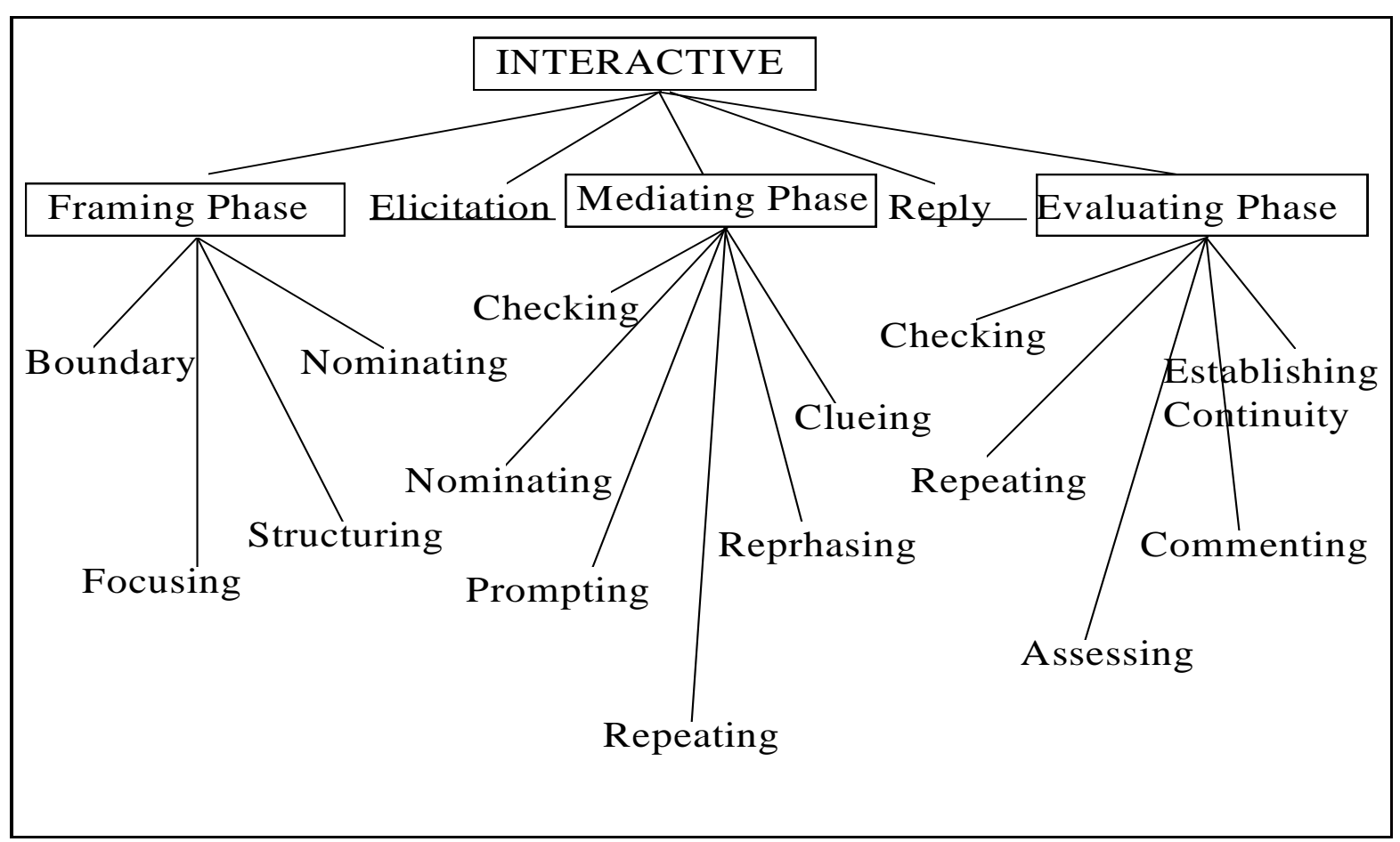

Figure 3: Phases in the Interactive Mode

The basic unit of the Interactive mode is the Interactive exchange defined in terms of topic where a change of topic initiates a new exchange. An interactive exchange is marked by an elicitation, that is an attempt on the part of the teacher to elicit information from one or more pupils and it usually takes the form of a question. The elicitation and the reply, if any, divide the exchange into three phases.

The first is the Framing Phase. In this phase ${ }_{2}$ the teacher prepares his pupils for the elicitation. The acts include marking boundaries (marking the boundaries of a new transaction by saying "OK", "Well", etc.), focusing (directing pupils' attention to a topic area and establishing communicative intentions), structuring (telling pupils how the transaction will proceed) and nominating (calling upon a pupil to answer).

After the elicitation, the pupils may fail to give a reply. The teacher may then go into the Mediating Phase where he further tries to elicit replies. The acts here are checking (checking if the elicitation is understood), prompting (urging a reply by saying "come on", "hurry up", etc.) clueing (providing additional information to help pupils give a reply), repeating the elicitation, rephrasing the elicitation if need be and nominating a pupil to answer.

When a reply is obtained, the teacher enters the Evaluating Phase. Here the teacher provides feedback to the reply obtained by employing various acts: checking (establishing whether a reply is intended by the pupil or understood by other pupils), repeating the reply, assessing (evaluating the accuracy/adequacy of the reply), commenting (expanding upon the reply) and establishing continuity (establishing relationship with the next exchange). All the teaching acts within a phase are potentially recursive and an exchange terminates when the teacher switches to another topic. 
The Operative Mode, which also elicits a response but this time a non-verbal one, is defined as giving instructions. Structurally, the utterance used in the operative mode are 'directives'. This usually takes the form of an order or an instruction. Figure 4 shows the phases in the Operative Mode.

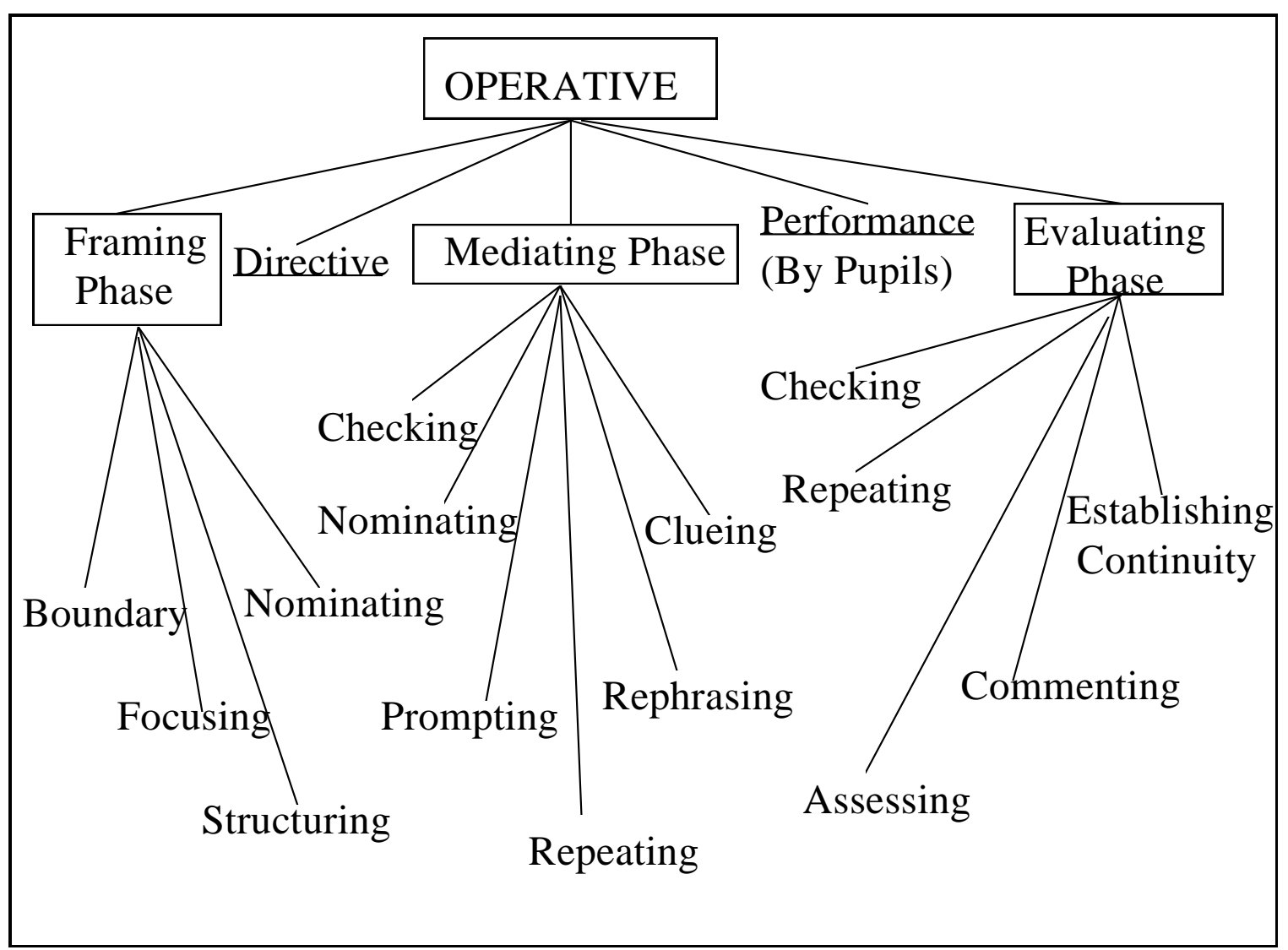

Figure 4: Phases in the Operative Mode

As in the interactive mode, an operative transaction is divided into the Framing Phase, the Mediating Phase and the Evaluating Phase. The Framing Phase prepares pupils for the instructions, the Mediating Phase ascertains whether or not the students understood what they are supposed to do while the Evaluating Phase determines whether or not the required activity has been carried out successfully. The teaching acts employed in this mode are the same as those in the Interactive Mode since both modes elicit responses.

The informative mode, on the other hand, calls for extended talk from the teacher in the form of a lecturette or from students giving reports. Figure 5 shows the different phases in the informative mode. 


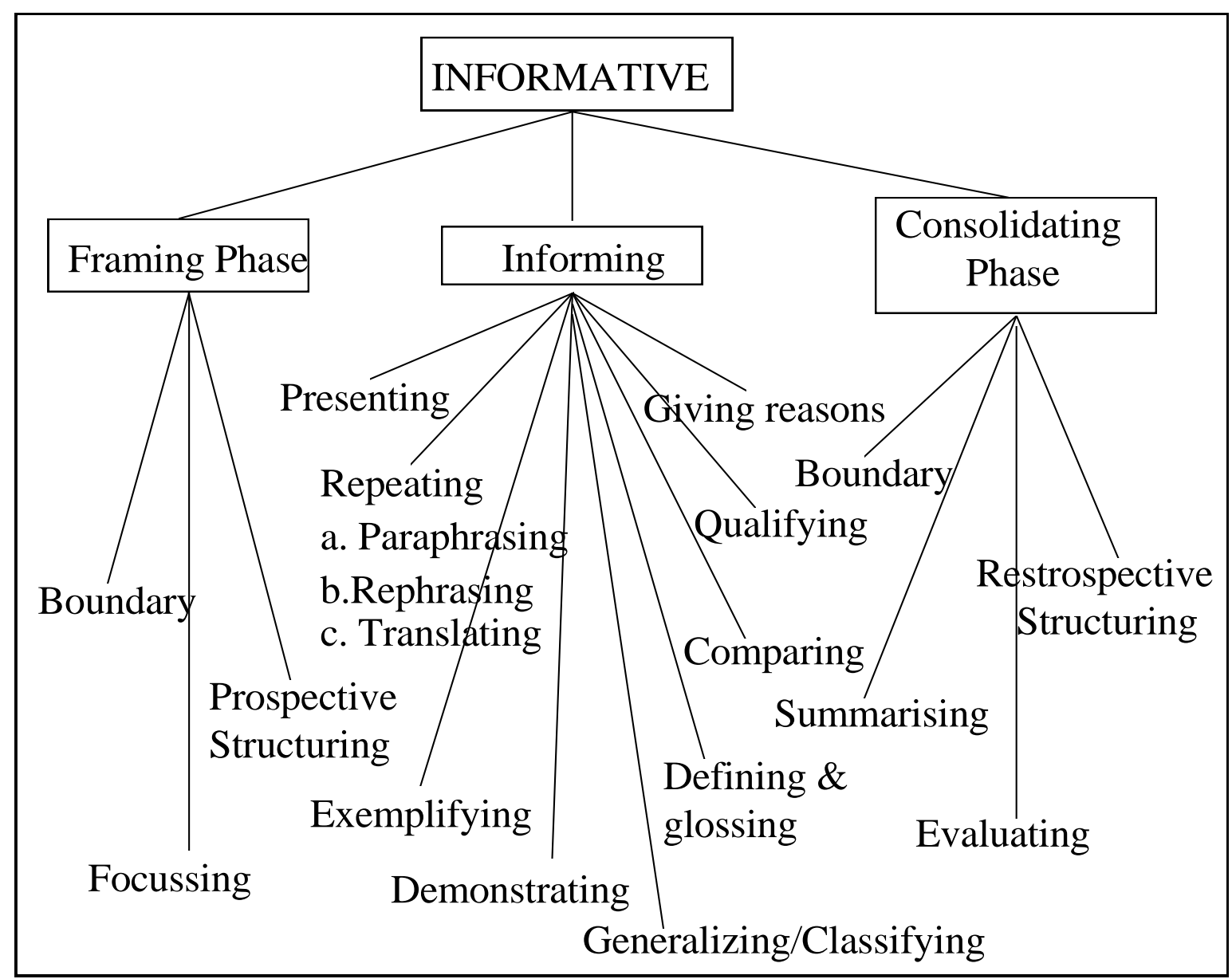

Figure 5: Phases in the Informative Mode

As in the other two modes, three phases are identified in the Informative Mode the Framing Phase, the Informing Phase and the Consolidating Phase.

The Framing Phase in the Informative Mode is the preparation phase. The teacher prepares the pupils for the information to be presented by employing the following acts: marking boundaries, focusing and prospective structuring. Of interest in this study is the prospective structuring since the teacher is expected to employ comprehensible input at this point. In the Informing Phase, the teacher presents the information. The acts within this phase include presenting, repeating which is further subdivided into paraphrasing, rephrasing and translating, exemplifying, demonstrating, generalizing, classifying, illustrating, defining and glossing, comparing and contrasting, qualifying and giving reasons. This particular phase will likewise bear close scrutiny for comprehensible input strategies employed by the teacher. The last phase is the Consolidating Phase where the teacher evaluates and summarizes what has been presented. The acts here are marking boundaries, summarizing, evaluating and retrospective structuring, the last of which is of interest in this study.

\section{THE CONCEPTUAL FRAMEWORK}

The conceptual framework of this study is based on Krashen's comprehensible input strategies and Hatch's Table of aspects of input, in the context of Johnson's (1986) concept of the pedagogical aspects of teacher verbal behavior and Chaudron's moves employed to make input comprehensible. The system of Sinclair and Coulthard which is designed for use in the analysis of classroom discourse was used in this study. Figure 6 which follows presents the comprehensible input strategies considered in this research. 


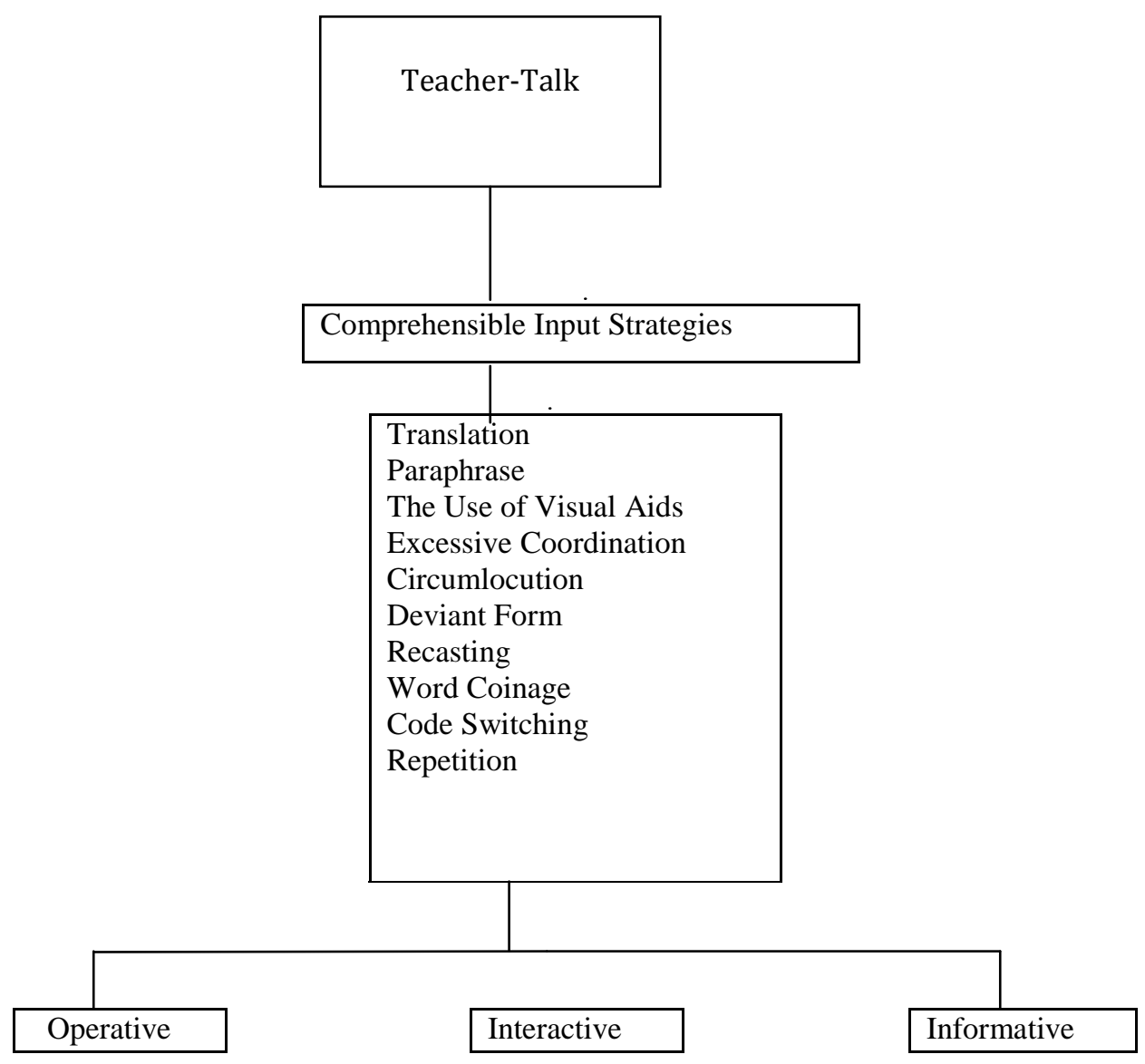

Figure 6: The Comprehensible Input Strategies in the Three Modes of Teacher Talk

\section{THE RESEARCH DESIGN}

As per the research design, it is hypothesized that the teaching experience of the mentors, the ability level of students and the pedagogical modes of teacher-talk serve as the independent variables in this study which will have an effect on the dependent variable namely, the choice of comprehensible input strategies used by the teachers to make scientific and abstract concepts comprehensible.

This descriptive study of classroom interaction drew mainly from Krashen's comprehensible input strategies and Johnson's model of pedagogical modes in teacher talk of the lessons observed. For analysis however, Sinclair and Coulthard's classroom discourse analysis system was utilized to analyze audiotape recordings of 12 high school science lessons. It looked specifically at the strategies employed to make input comprehensible. These included Chaudron's preformulations and reformulations in the interactive model, prospective and retrospective structuring in the informative mode and the monitoring and evaluative phases in the operative mode. The figure below shows the Research Design. 


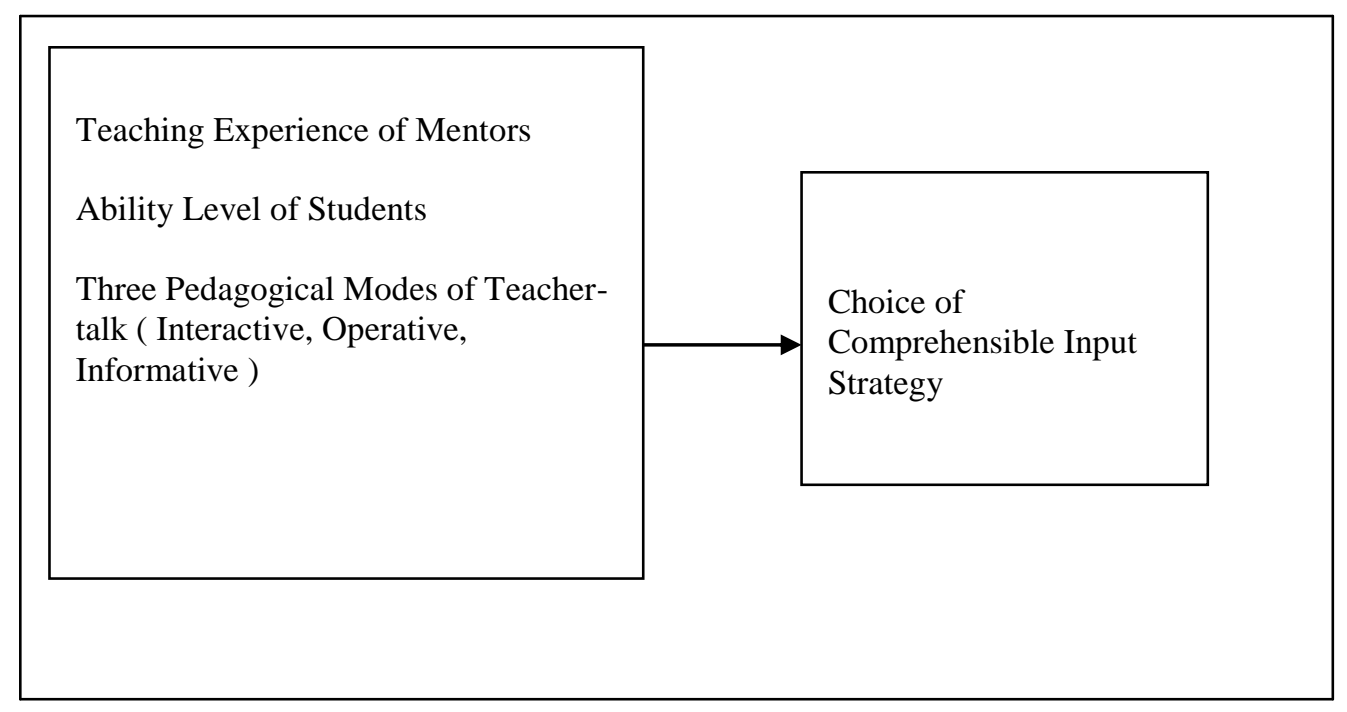

Figure 7: Research Design

\section{Samples of Extracts}

The following are the meanings of the acronym used:

ETHA - Experienced Teachers Handling High Ability Classes

ETLA - Experienced Teachers Handling Low Ability Classes

ITHA - Inexperienced Teachers Handling High Ability Classes

ITLA - Inexperienced Teachers Handling Low Ability Classes

Translation

One major strategy employed by the teachers, is the literal translation as shown in this example:

\section{Extract 1}

Type: Literal translation

Class: ETLA

Topic: Fats and Oil

T: What are the foods rich in protein Marvin? What are protein rich foods? 'Yong mayaman sa protina, Marvin?

M: $\quad$ Egg.

T: $\quad$ Egg. Yes, Egg is rich in protein.

In that example, the teacher first used the term protein-rich but decided to translate it to the target language to make certain that she was understood. The translation was literal (mayaman for rich) when a more appropriate translation would be"masustansya sa protein" or "sagana sa protein". In this type of translation, emphasis was placed on the lexicon and not on the concept.

Paraphrase

Paraphrase is a restatement of a text usually substituting more commonly used words for the expressions that may prove to be difficult in the original utterance as shown in the extract that follows.

Among the students in the low ability class, the inexperienced teachers used paraphrase to move the students from the layman's term of "become bigger" to the more scientific equivalent term "inflated" and "expand". This is shown in the extract that follows. 


\title{
Extract 2
}

\author{
Type: Paraphrase \\ Class: ITLA \\ Topic: How to Take in Air \\ T: What happens to the balloons inside this bottle? \\ S : $\quad$ Becomes bigger. \\ T: $\quad$ Okey. The balloons become bigger or it is inflated. Is it inflated or deflated? \\ S: $\quad$ Inflated. \\ T: $\quad$ The balloons which represent our lungs expand or it is inflated.
}

Use of Visual Aids

In Extract 3, which follows it might be noted that the inexperienced teacher made use of a prepared visual aid showing the internal structure of a leaf.

\section{Extract 3}

Type: Use of Visual Aids

Class: ETHA

Topic: Significance of Plants \& Chlorophyll in Photosynthesis

T: $\quad$ Where do you think class is the xylem?

S: $\quad$ (Students point to the xylem)

T: How about the phloem?

S: $\quad$ (Students point to the phloem)

T: Okey. That is the phloem. Together class, the xylem and the phloem is known as the vein.

Circumlocution

Circumlocution is the use of so many words to clarify the term the speaker has in mind. He does not go direct to the point. Instead, he tries to explain the term in a roundabout manner. This is shown in Extract 4 that follows.

\section{Extract 4}

Type: Circumlocution

Class: ETLA

Topic: Fats and Oil

T: What is the meaning of "translucent"?

S: $\quad$ Allowing the light to pass through but not transparent.

T: $\quad$ Yes, allowing the light to pass through but not transparent.

Do you understand that? When you see against the light, no. The translucent paper, you can what? The translucent paper you can what? The light allows to pass through but it is not transparent.

Deviant Forms

These are non-syntactic forms. In many instances, however, these are not really comprehensible input strategies but rather questioning strategies to secure the expected response. One deviant form is actually a leading question, which has the question word at the end of the sentence in order that the addressee knows what information is expected in his response. An example of this is given in Extract 5, which follows.

The novice teacher also made use of the incomplete prepositional phrase. However in the extract that follows, she actually makes use of two types of deviant forms: the question word and the incomplete prepositional phrase. 


\title{
Extract 5
}

\author{
Type: Deviant form (Question word and incompleteprepositional phrase) \\ Class: ITHA \\ Topic: How to Take in Air \\ T: What is happening when you inhale and then you exhale? Okey. There is a change in, a change in what, \\ brought about by? \\ S: $\quad$ Breathing. \\ Word Coinage
}

This is the use of a term familiar to the learners in order to clarify a concept or a science term being taught by the teacher. This is shown in Extract 6a, which follows.

\section{Extract 6}

Type: Word Coinage

Class: ETHA

Topic: Plant and Animal Organ and System

T: What is the major function of a stem?

S: $\quad$ The path .... the path

T: Okey. All right. The pathway, it is the pathway where the water and mineral goes up from the root to the other parts of the plant. We call that transport carrier.

In extract 6, the experienced teacher coined the word transport carrier to show the function of the stem, which the class earlier referred to as a path or pathway. In English, a transport carrier would mean a vehicle that holds transports in much the same way that an aircraft carrier is a ship that carries airplanes or a ferry boat that carries cars and trucks across rivers or lakes. In this case, however, the teacher refers to the stem as a "transport carrier" because minerals and water pass through it to the other parts of the plant.

Code switching

This is the shift from the second language (L2) to L1 to make the meaning clear. This may be seen in Extracts 7 that follows.

\section{Extract 7}

Type: Code switching

Class: ITHA

Topic: Significance of Plants and Chlorophyll in Photosynthesis

T: $\quad$ This means that the chlorophyll is in alcohol. Wala na sa dahon, kundi nasa alcohol na. Actually, meron pa 'yong dahon, pero konti na lang.

\section{Excessive Coordination}

This refers to the use of too many conjunctions or linkers resulting in a long, run-on sentence in giving instructions. This is shown in Extracts 8, which follows.

\section{Extract 8}

Type: Excessive coordination

Class: ETHA

Topic: Fats and oil

T: $\quad$ Get the oil and then you get the samples of nuts and seeds, then add ethyl alcohol and then you stand it for 12 hours, no, and then you are going to filter the extract and then you fill water and then what will happen to the water? 


\title{
Recasting
}

This refers to syntactic revisions made by the teacher in order to clarify an utterance or an expression. Sometimes the revision took the form of changing questions seeking information into imperatives or commands as shown in Extract 9 where the teacher initially asked through a question an example of food rich in carbohydrates. She followed this immediately with a recast version, this time in the form of a command.

\section{Extract 9}

\author{
Type: Recasting \\ Class: ETHA \\ Topic: Fats and Oil \\ T: $\quad$ What about the example of the carbohydrate or the foods that are rich in carbohydrates? Give me examples \\ of the food rich in carbohydrates. \\ S: $\quad$ Ma'am, fried rice
}

Repetition

This is the act of repeating words and phrases until the intended meaning is conveyed. While it may seem that repetition per se would not help make an utterance comprehensible since no change was made on the original text, nonetheless, repetition enables the listener to focus on what was uttered and provides him with wait time to formulate a response.; hence, it is included here as one of the strategies employed by the teacher to enable the students to respond to what was said.

\section{Extract 10}

Type: Repetition

Class: ETLA

Topic: Fats and Oil

T: How about the liquid? What will you do with the liquid sample? What will you do with the liquid sample?

\section{Findings}

1. Is there a difference in the comprehensible input strategies used by teachers in the three pedagogical modes?

The study revealed that in at least four of the ten comprehensible input strategies employed in the study a significant difference was noted across the three pedagogical modes. These were translation, use of visual aids, excessive coordination and recasting. In so far as those strategies were concerned it might be pointed out that the pedagogical mode affected the choice of comprehensible input strategy employed by the teacher. Other findings along this line were as follows:

- $\quad$ The interactive mode which entailed spontaneous negotiation of meanings among the interactants called for the frequent use of recasting, deviant forms, translation, paraphrase, code switching, (in the case of novice teachers) and repetition.

- $\quad$ Because of the nature of the discourse, excessive coordination was used in the operative mode where a series of steps to follow was given in laboratory work. In contrast, no use was found for it in the informative mode by either group and it was very minimally used in the interactive mode by novice teachers.

- $\quad$ Visual aids were used in all three modes by both groups .However, experienced teachers made greater use of visual aids in the operative mode followed by the informative mode and lastly, by the interactive mode. In contrast, the novice teacher used it extensively in the informative mode and only moderately in the interactive and operative modes. Therefore, the use of visual aids was acknowledged important as a comprehensible input strategy irrespective of the pedagogical mode, and preference for its use was to some extent conditioned by the nature of the discourse in the pedagogical mode. 
- $\quad$ Circumlocution and word coinage were used only minimally by both groups across all three modes. No consistent pattern emerged as to the preference for their use among the novice teachers. In fact, the first of these had the same frequency of occurrence across the three modes. With the experienced teachers, however, both circumlocution and word coinage were employed most often but minimally in the informative mode followed by the interactive mode and lastly by the interactive mode. So, it may be said that these two strategies were not popular among the subjects of this study nor was their use conditioned by the nature of the pedagogical mode.

No consistent pattern of preference for the use of code switching was evident in the data gathered across pedagogical modes. Among the experienced teachers it was minimally used in decreasing frequency in the informative followed by the interactive and finally by the operative mode. With the novice teachers it was used moderately in the interactive mode, minimally in informative mode and least often in the informative mode. So, preference for its use cannot be said to result from the nature of the mode. In the case of repetition, the data shows a greater preference for it in the interactive mode than in the other two modes. This is attributed to the nature of the discourse in the interactive mode where questions are raised and answers are expected. However, when answers are not forthcoming then the questions are repeated either to ensure that they were heard or to afford the listener sufficient wait time to process the response.

2. Does the length of teaching experience affect the choice of comprehensible input strategies to use in the three modes?

In this study, the length of teaching experience of the two groups of teachers who served as subjects: namely, the experienced and the novice teachers did not affect their choice of comprehensible input strategies to employ in the three modes of teacher- talk. Both groups employed comprehensible input strategies but the statistical test revealed no significant difference in their preference of strategies to use.

For instance, for the experienced teachers translation came first although less frequently them among the novice teachers recasting was the second and paraphrase was the third. For the novice teachers recasting was first with very minimal difference with translation which came next in frequency and paraphrase which ranked third. The other comprehensible input strategies use of visual aids, deviant forms, repetition, code switching, word coinage, circumlocution and excessive coordination showed no statistically significant difference across groups.

3. Does the ability level of students affect the teacher's choice of comprehensible input strategies?

Of the 10 comprehensible input strategies employed in the classes observed in this study, only two, namely translation and the deviant forms revealed statistically significant difference in the frequency of use in low and high ability level classes. In fact, the use of translation proved to be statistically significant at the .05 level not only across pedagogical modes but also between the two ability levels. As might be expected, teachers handling low ability level classes used it more often that those handling high ability classes. As pointed out earlier, experienced teachers handling high ability classes desisted from resorting to the use of L1 as much as possible. Instead, they fell back on other strategies like recasting and paraphrase which still called for the use of L2.

An even higher level of statistical difference was noted in the use of deviant forms. Not only was it used more extensively in high ability classes with a ratio of 3 to 1 compared to low ability classes, it also came in varied forms where sentence structures were concerned. These were putting the question word in final instead of in initial position to call attention to the desired response or leaving a statement incomplete for the students to provide the missing item or the object of the preposition.

4. Which of the determinants are significant in the choice of comprehensible input strategies in a science class?

The choice of comprehensible input strategies in teaching science classes was found not to be affected significantly by the length of service of the teachers, but by the ability level of the students and the pedagogical mode or combination of modes concerned in a particular lesson. 
While experienced teachers employed more comprehensible input strategies than the inexperienced ones and could be attributed to the fact that their experience in teaching has equipped them with strategies to used, the inexperienced teachers also had a host of strategies at their command probably from pre-service courses they attended.

In contrast, the ability level of student determined significantly the choice of comprehensible input strategies employed by the teachers. High ability students were perceived as capable of coping with the lesson, therefore, less comprehensible input strategies were needed by the teachers. On the other hand, the low ability students were in the need of more comprehensible input strategies from their teachers so that they would be able to understand the science concepts being taught. These strategies help to facilitate the learning of science.

Lastly, the pedagogical modes called for particular comprehensible input strategies because of the nature of the discourse. This was evident in the significant difference in the choice of strategies across modes.

\section{CONCLUSIONS}

Based on the findings, the following conclusions are made concerning the choice of comprehensible input strategy employed by experience and novice teachers in their classes:

1. In line with the pedagogical modes

It might be said that the nature of the pedagogical mode affects the choice of comprehensible input strategy to employ. In the interactive mode, the comprehensible input strategies_found to be favored were: recasting, deviant forms, translation, paraphrase, code switching and repetition. However, two of them - use of deviant forms and repetition - were more of questioning strategies. This also confirms Bacungan's (1983) study in the discoursal strategies were repetition and restatement were frequently used.

In the operative mode, excessive coordination was the comprehensible input strategy frequently used to connect the different steps in a given set of instructions.

The conjunctions then, and then served to mark time sequence. Once more in this case, it is the nature of the discourse that affects the choice of strategy to employ since excessive coordination was not used in the informative mode and was employed only minimally in the interactive mode not so much to show time sequence but to elicit additional information.

Although the use of visual aids was favored across all three pedagogical modes, experienced teachers used it more frequently in the operative mode while novice teachers made more frequent use of it in the informative mode. Both groups used visual aids minimally in the interactive mode and this could be attributed to the nature of the discourse.

In the informative mode, the preferred comprehensible input strategies employed were the use of visual aids, translation and paraphrase. The first of these made the lecturette clearer and the two other strategies aided in the comprehension of the talk.

2. In consideration of the ability level of students

The ability level of the students affected the teacher's choice of comprehensible input strategy to employ. With the high ability group of students the use of deviant forms was favored but more as a questioning strategy to provide the students with a clue as to the expected response to a question. On the other hand, translation was less frequently used by experienced teachers handling high ability groups compared to the other teachers. In fact the former resorted to translation only after attempting to employ other strategies that made use of L2 such as paraphrase and recasting.

3. In relation to teacher's experience 
The number of years of teaching experience of the science teachers in this study yielded no significant difference in the choice of comprehensible input strategies employed in the three pedagogical modes. This shows that content area teachers lack awareness of the fact that even as they teach concepts, they also provide a setting where students may acquire proficiency in the language used to teach those concepts. Their main concern is content as it should be but given the provisions of the National Bilingual Education Policy, they miss out on the possibility of their being catalysts for the acquisition of the language of science as well. This could be attributed to a lack of training in this area in their pre-service education courses. Thus, Science teachers focus on content not on form.

4. In relation to the determinants

There are two determinants which are significant in the choice of comprehensible input strategies in a science class. These are the ability level of the students, and the three pedagogical modes of teacher-talk: the interactive, the informative and the operative.

\section{Implications}

From the aforementioned conclusions may be drawn the following implications:

1. Although sub-consciously the science teachers adopted comprehensible input strategies suited to the pedagogical modes, greater awareness on their part of comprehensible input strategies would result not only in their students' comprehending content but also picking up the second language. Content area teachers like those who teach Science where English is used as medium of instruction play a dual role. They not only teach concepts but they also provide a venue for language acquisition

2. While the use of the native language helps in clarifying concepts, frequent use of code switching and translation does not enable the students to make sense of utterances in L2. There are other comprehensible input strategies like paraphrase and recasting that may first be tried out before resorting to the use of the native language. In this study experienced teachers handling high ability level classes were aware of this, hence, they opted to rephrase and recast their sentences and they only translated into L2 as a last resort. Unless content area teachers are made aware of the fact that they, too, play a significant role as communication models in L2, they will continue to use L1 as a means of eliciting correct responses from the students.

3. Visual aids or realia served as aids in both the informative and the operative modes. In this study, they were used mainly to clarify a concept.

4. While science teacher, experienced or inexperience focused on content or meaning not on form or structure, they nonetheless aided in enabling students to comprehend concepts by resorting to comprehensible input strategies.

\section{RECOMMENDATIONS}

Considering the conclusions arrived at in this study and their implications in the use of English on a content area class like Science, the following recommendations are offered:

\section{For Further Study}

With the current emphasis on learner-centered approaches, suggestions have been made to take into consideration the learning preferences of students. Since the teachers in this study employed different strategies with the two groups of students, another study could be undertaken to determine student preferences and how these may facilitate not only the learning of science concepts but also skill development in English. Moreover, since this is an exploratory study in the secondary level, this could be replicated in the tertiary level to find out what comprehensible input strategies are employed with more mature students. While studies in bilingual education have shown that initial literacy in L1 could result in transfer of cognitive skills in L2 in accordance with Cummin's Interdependence Hypothesis (1986) and although science as a process may be taught in one's L1, it has been pointed out that science as a discipline is best taught using the language in which materials are originally written, in this case, English. 


\section{For Language Policy and Language Education}

There is a need to review the pre-service curricula of content area majors where English is used as medium of instruction to determine if provision is made for "the language of science" and classroom interaction strategies. The Philippine Commission on Educational Reform (PCER) is recommending the use of the native language for initial literacy. Guidelines as to when and how the transition will be made from the use of L1 to the use of L2 in Science should be informed by research in that area. As was mentioned earlier, in the lower grades where science is taught as a process, the use of L1 is preferred but a shift has to be made to L2 when science is taught as a discipline.

Instructional materials in science should consider not only the content but also comprehensible input strategies to make sense of the language used to express that content.

Finally, the continuing education of science teachers could include sessions on English for Science and Technology to help science teachers develop their own linguistic capacities in their discipline. The skills they develop can then be applied in the handling of their subjects.

\section{AUTHOR INFORMATION}

Dr. Crisanta C. Buri finished Doctor of Education, major in Educational Administration, Masters of Arts in Education, major in English, Bachelor of Science In Education, major in English. She has taught since 1978 up to the present in the secondary and the tertiary levels. She has presented this paper in several international conferences, twice in USA, in TESOL and The Clute Institute and twice in Asia: Thailand and Malaysia (ASIA TEFL). She has attended seminars, trainings, conferences local and abroad to keep herself abreast of what is going on in her field of specialization, English and other allied subjects like ESL/EFL and ESP. E-mail: saniben_18@yahoo.com

\section{REFERENCES}

1. Allwright, R. L. 1980. "Turns, Topics and Tasks: Patterns of Participation in Language Learning and Teaching," in D. Larsen - Freeman (ed). Discourse Analysis. Rowley, Mass.: Newbury House.

2. Bacungan, Amy D. 1986. "Discourse Patterns in teaching mathematics classes", Ph.D. Dissertation. Quezon City: University of the Philippines.

3. Bailey, L. and Kathleen M. 1985. "Classroom-centered research on language teaching and learning”, In M. Celce-Murcia (ed). Beyond Basics. Rowley, Mass: Newbury House.

4. Bellack, Arno A., H. N. Kliebard, R. T. Hyman and F. Smith, Jr. 1966. The Language of the Classroom, New York: Teachers' College Press of Columbia University.

5. Brinton, Donna M. etal 1989. "Content-Based Second Language Instruction”. New York: Newbury House Publishers.

6. Brown, R. and C. Hanlon (1970) "Derivational complexity and order of acquisition in child speech. "In J. Hayes (Ed.) Cognition and Development of Language. New York

7. Canale, Michael and Merrill Swain. 1980. "Approaches to Communicative Competence". Occasional Papers, Singapore: SEAMEO- RELC.

8. Chamot, Anna U. and J.M. O’Malley. 1988. "The cognitive academic language learning approach: A bridge to the mainstream", TESOL Quarterly

9. Chaudron, C. 1977. "Teachers' priorities in correcting learners' errors in French immersion classes". Working Papers on Bilingualism, $12: 21$ - 44.

10. Chaudron, Craig. 1988 Second Language Classrooms: Research on Teaching and Learning. Cambridge University Press.

11. Coulthard M. 1977. An Introduction to Discourse Analysis. London: Longman.

12. Croft, Kenneth. 1980. Readings in English as a Second Language for Teachers and Teacher Trainees. Boston: Little Brown and Co.

13. Cummins, Jim and Merill Swain, 1986. Bilingualism in Education: Aspects of Theory, Research and Practice. London: Longman.

14. Das, Bibran K. (ed). 1987. Patterns of Classroom Interaction in Southeast Asia. Singapore: SEAMEO RELC. 
15. Diamante, Louella C. 1992. "A Descriptive Analysis of Pedagogical Mode and Treatment Errors in Selected Science Classes: Towards a Theory of Language Acquisition. Ph.D. Dissertation. Quezon City: University of the Philippines.

16. Dube, Lilia S. 1974. "Moves and strategies in a principle venture in secondary school mathematics, monograph no. 1. Quezon City: UP Science Education Center.

17. Dube, Lilia. 1971. "Moves and strategies in a principle venture in secondary school mathematics". Ph. D. Dissertation. Urbana, Chicago: University of Chicago.

18. Edwards, A. D. and D. P. G. Westgate. 1987. Investigating Classroom-Talk. London: The Falmer Press.

19. Ellis, Rod. 1980. "Classroom interaction and its relation to second language learning". RELC Journal.

20. Ervin - Tripp S. 1976. "Some Strategies for the First and Second Years". In A. Di. (ed). 1 Language Acquisition and Communicative Choice. Stanford University Press.

21. Flanders, Ned. A. 1970. Analyzing Teaching Behavior. Reading, Massachusetts: Addison-Wesley.

22. Foronda, Belen. 1990. "Strategies employed by teachers to develop cognition and metacognition among secondary science students." Masters Thesis. Quezon City: University of the Philippines.

23. Gaies, S. 1983 "Learner Feedback: An Exploratory Study of its role in the Second Language Classroom “. In H. W. Seliger and M. H. Long (eds). Classroom Oriented Research in second Language Acquisition Rowley, Mass :Newbury House, 190 - 2

24. Gonzales, Andrew and Sibayan, Bonifacio (eds.) 1985. Evaluating Education in the Philippines. Manila: Linguistic Society of the Philippines.

25. Hamayan, Else and Tucker G. Richard, 1980. "Language input in the bilingual classroom and its relationship to second language achievement. "TESOL Quarterly.

26. Hatch, Evelyn, 1978. "Discourse Analysis and second Language Acquisition: A Book of Readings. Rowley, Mass.: Newbury House.

27. Johnson R. K., R. M. K. Chan and Chek. 1985 "Language across the curriculum in teacher education". Paper presented to the 20th RELC Regional Seminar. Singapore: SEAMEO - RELC.

28. Krashen, Stephen D. 1981. Second Language Acquisition and Second Language Learning. Pergamon Press.

29. Krashen, Stephen D. 1982. Principles and Practice in Second Language Acquisition Oxford: Program Press :

30. Lapp, Dione, James Flood and Nancy Farmon. 1990. Content Area Reading and Learning: Instructional Strategies. Englewood Cliffs., N.J.: Prentice Hall.

31. Maminta, Rosario E. 1985. "Forms and functions in concept venture in Science and Mathematics". Occasional Papers. Singapore: SEAMEO - RELC.

32. Manalo, Eppie. 1990. "Cognitive and effective behaviors of effective language teachers." Ph.D. Dissertation, Quezon City: University of the Philippines.

33. Mogul, Martha, E. Tuy, L. Santos and C. Esclaban, 1977. "Verbal interaction in English and Filipino: A study of classroom discourse in Science and Mathematics in four grade levels," Ph.D. Dissertation. Quezon City: University of the Philippines.

34. O'Malley, Michael J., et al. 1985. Learning Strategy Applications with Students of English as a Second Language. TESOL Quarterly.

35. Seliger, Herbert W. 1983. "Classroom - centered research in language teaching: Two articles on state of the art". TESOL Quarterly, 17: 2 (June)

36. Seliger, H. W. and M. H. Long (eds). 1983. Classroom Oriented Research in Second Language Acquisition. Rowley, Mass.: Newbury House.

37. Sinclair, J. McH. and R. M. Coulthard. 1975. Towards an Analysis of Discourse. London: Oxford University Press.

38. Sinclair. J. and Brazil. 1982. Teacher Talk. London: Oxford University Press.

39. Stern, H. H. 1978. "What can we learn from the good language learner?" Canadian Modern Language Review.

40. Swain, Merrill. 1980. Future Directions in Second Language Research.

41. Tarone, Elaine. 1977. "Conscious communication strategies in inter-language". Teaching and Learning English as a Second Language: Trends in Research and Practice. On TESOL. 1977. Washington D. C.

42. Van Di JK, Teun A. (ed). 1985. "Dimensions of Discourse". Handbook of Discourse Analysis, Vols. 1 - 4. London: Academic Press. 